\title{
CONTRIBUIÇÕES DOS TRABALHOS DE FIM DE CURSO DE ENGENHARIA DE PRODUÇÃO DE UMA UNIDADE DE ENSINO DESCENTRALIZADA
}

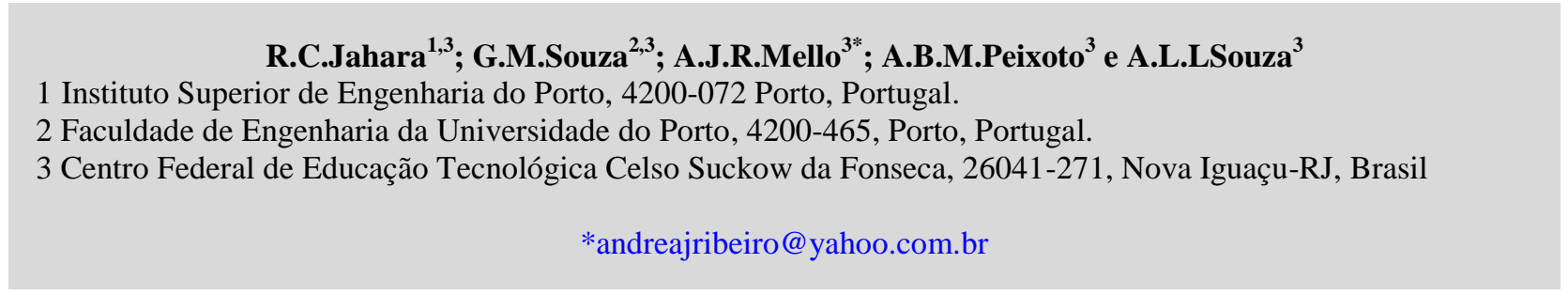

\section{RESUMO}

Este estudo tem o objetivo de realizar um estudo bibliométrico, identificando as áreas de formação do curso que mais foram estudadas pelos alunos do curso de Engenharia de Produção implantado em 2005 como estratégia de interiorização do Ensino Superior no Rio de Janeiro. O estudo caracteriza-se como um trabalho documental, descritivo-exploratório, que trata de dados que foram coletados dos projetos de final de um curso de
Engenharia de Produção de uma instituição de ensino superior federal localizada no município de Nova Iguaçu, Rio de Janeiro. Através de uma analise bibliométrica, foi possível identificar que no curso de Engenharia de Produção da unidade descentralizada Nova Iguaçu, as áreas temáticas de Qualidade, Logística e Engenharia Organizacional como as que mais atraíram e motivaram os alunos.

\section{CONTRIBUITIONS OFACADEMIC FINAL PROJECTS AT A GRADUATED PRODUCTION ENGINEERING COURSE OF A DECENTRALIZED INSTITUTION}

\begin{abstract}
This study aims to carry out a bibliometric study, identifying the course of the training areas that were studied by the students of Production Engineering course implemented in 2005 as internalization strategy of higher education in Rio de Janeiro. The study is characterized as a documentary work, descriptive and exploratory, which deals with data that were collected from the final projects
\end{abstract}

of a Production Engineering course of a federal higher education institution located in the municipality of Nova Iguaçu, Rio de Janeiro. Through a bibliometric analysis, the study identified that in the course of decentralized unit Production Engineering Nova Iguaçu, the thematic areas of quality, logistics and organizational engineering, such as those more attracted and motivated students.

KEYWORDS: final course projects; production engineering; themes. 


\section{INTRODUÇÃO}

A Engenharia de Produção tem se apresentado como uma das áreas que mais crescem tanto em quantidade de ingressantes no mercado de trabalho quanto com a contribuição cientifica que o curso tem trazido para a sociedade. As pesquisas tem refletido um grau de amadurecimento que possibilita e desafia aos alunos de graduação a elevarem a qualidade de seus projetos finais. Dentro da perspectiva de crescimento e evolução do curso Oliveira (2005) e Sousa (2012) enfatizam o papel da Engenharia de Produção enquanto curso que surge como resposta as demandas da sociedade.

Quanto a questão da formação em Engenharia de Produção e o mercado de trabalho associado a ela, tem-se os trabalhos de Faria (2004), Costa (2009) e Nigro e Valente (2008) que se preocupam a avaliar os caminhos da empregabilidade dos egressos do curso. A preocupação com os egressos não é nova, ela tem varias faces, desde o ingresso do aluno na Universidade até o final do curso, ronda a ele o perigo da evasão, seja por problemas financeiros, geográficos e até mesmo de identificação com o curso.

Passando a fase critica, surge o encaminhamento a reta final do curso, onde o aluno começa a se encaminhar para áreas que ele mais se identifica, que mais gosta. Nesse momento, o risco da evasão reduziu, mas surgem outros temores, tal como o emprego no final do curso, aprovação nas disciplinas de final de curso para não atrasar a formatura e até mesmo a escolha do tema da monografia. É justamente a escolha do tema da monografia que se coloca como objeto central desta investigação.

Este objeto se torna relevante a medida que o estudo trata de um curso criado em uma unidade de ensino descentralizada, dentro do programa de interiorização do ensino superior no país. Estudos como este trazem informações sobre os cursos criados, bem como evidencia as trajetórias acadêmicas que se desenvolveram. É justamente no momento de reta final do curso, onde os alunos precisam definir seus orientadores e seus temas de pesquisa que torna-se crucial o amadurecimento acadêmico, e que a vivência acadêmica e profissional do aluno pode ou não ser a motivação para a definição de seu tema de projeto final.

Portanto, este estudo tem o objetivo de realizar um estudo bibliométrico, identificando as áreas de formação do curso que mais foram estudadas pelos alunos do curso de Engenharia de Produção implantado em 2005 como estratégia de interiorização do Ensino Superior no Rio de Janeiro. Ou seja, após 10 anos de existência e como resultado de uma política pública, qual tem sido o foco dos projetos dos estudantes e quais motivações para a definição e escolha do tema?.

Este trabalho apresenta relevância a medida que sinaliza a direção acadêmica que os alunos tem optado, ou seja, a preferência dos alunos no que tange a elaboração do trabalho final de curso permite identificar se há balanceamento ou não na formação, visto que os alunos tendem a optar desenvolver os temas que possam ser percebidos como mais relevantes. Com isso, surge uma possibilidade de identificar e corrigir alguma falha que possa existir no processo de ensinoaprendizado. Mello e Santos (2015) apontam que não enxergar ou ignorar as demandas da sociedade no ato de estruturar o projeto pedagógico é uma das principais deficiências que uma universidade pode apresentar.

\section{REVISÃO BIBLIOGRÁFICA}

\subsection{O Campus Nova Iguaçu como estratégia de Interiorização do Ensino Público}

A Unidade de Ensino Descentralizada de Nova Iguaçu do Centro Federal de Educação Tecnológica Celso Suckow da Fonseca foi inaugurada oficialmente em 22 de agosto de 2003, como 
parte do compromisso do Governo Federal em promover o avanço da interiorização da educação pública federal nos níveis técnico e superior (Pires et al., 2007).

O referido programa na região propunha a articulação de três tradicionais Instituições Federais de Ensino Superior (IFES) do Estado do Rio de Janeiro - Universidade Federal Fluminense (UFF); Centro Federal de Educação Tecnológica Celso Suckow da Fonseca (CEFET/RJ); Universidade Federal Rural do Rio de Janeiro (UFRRJ) - para a implementação de unidades avançadas, capazes de suprir as evidentes demandas da população por uma educação de excelência (Dias e Araujo, 2008).

Contudo, foi somente em 2004 que o CEFET/Nova Iguaçu iniciou as atividades acadêmicas de seus cursos regulares, após realização de concursos para docentes, servidores técnicosadministrativos e alunos. No referido ano foram implantados quatro cursos técnicos, em paralelo ao ensino médio e a um curso de graduação em engenharia industrial de controle e automação. O curso de engenharia de produção da UnED/NI seria aberto à sociedade no ano seguinte.

Atualmente, a UnED/ NI opera em 3 turnos diários e dispõe de mais de 100 docentes, a maioria contratada em regime de dedicação-exclusiva, para atendimento a, aproximadamente, quase 2.000 alunos distribuídos entre os seguintes cursos:

- Ensino médio (antigo $2^{\circ}$ grau);

- Técnico (Enfermagem; Informática; Automação; Telecomunicações);

- Nível Superior (Engenharia de Produção; Engenharia Industrial de Controle e Automação e Engenharia Mecânica).

Cumpre destacar que os cursos de graduação do CEFET/RJ UnED/NI são os únicos bacharelados em engenharia públicos federais oferecidos na Baixada Fluminense, área periférica da região metropolitana do Rio de Janeiro. Esta característica distintiva cria oferta de cursos de qualidade em uma região desprovida de ensino público federal de nível técnico e na área de Engenharia, ofertando ensino e pesquisas de excelência em uma área mais carente.

\subsection{Breve contextualização histórica da Engenharia de Produção}

Segundo a Associação Brasileira de Engenharia de Produção (ABEPRO), a origem da Engenharia de Produção (EP), originária da chamada Engenharia Industrial, ocorreu nos EUA, na virada do século XIX para o século XX, inserida em um processo de avanço da industrialização e do crescimento econômico. Dessa forma, pode-se dizer, conforme argumenta Mello e Sousa (2015) que a Engenharia de Produção surge como uma resposta a uma série de demandas industriais emergentes, especialmente relacionadas à solução de problemas de ordem tecnológica e/ou administrativa, nos processos fabris.

Sob o ponto de vista histórico, a Engenharia de Produção (EP), enquanto curso de Graduação, é recente. Até meados da década de 1970, só existiam cursos de pós-graduação e os de graduação tinham a Produção como habilitação ou ênfase de outra modalidade de Engenharia, principalmente da Engenharia Mecânica. Oliveira (2005) aponta a expansão da EP enquanto curso de graduação deveu-se ao conhecimento, que se tornou matéria prima para o mundo pós moderno, cada vez mais competitivo, onde as empresas buscam melhoria contínua de processos, métodos, fluxos, produtos e de outros aspectos que norteiam as áreas do conhecimento abrangidas pela EP. O mesmo autor complementa dizendo que "a natureza do conhecimento de engenharia ("problem solving”) torna a Engenharia de Produção aquela que melhor atende às organizações na atualidade 
em termos de articulação de suas funções clássicas - mercado, finanças, pessoas e produção integrando-as ao conhecimento tecnológico e o sistêmico."

Assim como nos EUA, no caso do Brasil, seu surgimento e consolidação se devem, em grande medida, ao crescimento industrial e econômico do país. A instalação de muitas empresas multinacionais no país na década de 50 do século XX assegurou o contexto necessário para impulsionar o surgimento do primeiro curso de engenharia de produção do país, na Escola Politécnica da USP.

Segundo Relatório do Confea (2010), essa iniciativa foi seguida por outras instituições de ensino, que começaram essa jornada pela incorporação de disciplinas relativas à EP em outros cursos de pós-graduação e de graduação, na UFRJ (em 1957) e na PUC-Rio (em 1962), respectivamente. Na década de 70 do século XX, o Conselho Federal de Educação determinou que a Produção seria uma habilitação das cinco grandes áreas de engenharia: mecânica, química, elétrica, metalúrgica e civil.

E somente no início do século seguinte, em 2004, iniciam-se as discussões e apreciações que convergiram para a votação de um projeto de resolução em que se reconhece na categoria profissional de engenharia o campo profissional da modalidade Produção (http://www.epr.crp.ufv.br/), embora a Engenharia de Produção Plena, como graduação autônoma, tenha tido início ainda na década de 70, também na Escola Politécnica da USP (Confea, 2010).

Desde seu surgimento, o quantitativo de cursos existentes vem aumentando consideravelmente, com um crescimento vertiginoso a partir de 1998 (Oliveira et al., 2005), chegando-se em 2013 com um total de 585 cursos de engenharia de produção registrados e em atividade no Brasil (Mello e Sousa, 2015), reforçando a importância da existência de processos avaliativos que primem pela manutenção da qualidade na educação.

Segundo a ABEPRO (2008), o objetivo de um curso de engenharia de produção consiste em formar profissionais habilitados ao projeto, operação, gerenciamento e melhoria de sistemas de produção de bens e serviços, integrando aspectos humanos, econômicos, sociais e ambientais. E entende-se que para isso, o estágio curricular supervisionado exerce papel fundamental, permitindo que os estudantes vivenciem na prática o que lhes é ensinado em sala de aula.

\subsection{As Subáreas da Engenharia de Produção}

Segundo Mello e Santos (2015) a universidade como instituição de ensino tem por objetivo, entre outros, a transmissão do conhecimento aos que o buscam, fazendo-se presente em vários contextos. O saber é algo que pode ser adquirido de diversas formas, assim como o ensino se desdobra em diversas maneiras. No caso da Engenharia, há os conteúdos disciplinares básicos e os profissionalizantes. No que se refere a base profissionalizante, segundo a ABEPRO (2008), a Engenharia de Produção possui uma base científica e tecnológica própria que a caracterizam como grande área, na qual o perfil do egresso contemple uma sólida formação científica e profissional geral, que o capacite a identificar, formular e solucionar problemas com visão ética e humanística.

Nesse processo de formação, os estudantes de engenharia de produção se deparam com conhecimentos relativos a 10 (dez) subáreas listadas pela ABEPRO, cada qual com seu foco específico, no quadro 1, tais como: engenharia de operações e processos da produção; logística; pesquisa operacional; engenharia da qualidade; engenharia do produto; engenharia organizacional; engenharia econômica; engenharia do trabalho; engenharia da sustentabilidade e, por fim; educação em engenharia de produção. 


\begin{tabular}{|l|l|}
\hline \multicolumn{1}{|c|}{ SUB-ÁREAS } & \multicolumn{1}{|c|}{ FOCO } \\
\hline $\begin{array}{l}\text { Engenharia de operações e } \\
\text { processos da produçáo }\end{array}$ & $\begin{array}{l}\text { Projetos, operação e melhoria dos sistemas que criam e entregam os serviços } \\
\text { e produtos primários da empresa }\end{array}$ \\
\hline Logística & $\begin{array}{l}\text { Técnicas apropriadas para tratamento de questões envolvendo transporte, } \\
\text { movimentação, estoque e armazenagem de insumos e produtos }\end{array}$ \\
\hline Pesquisa operacional & $\begin{array}{l}\text { Resolução de problemas reais envolvendo necessidade de tomada de decisão } \\
\text { com o apoio de modelos matemáticos }\end{array}$ \\
\hline Engenharia da qualidade & $\begin{array}{l}\text { Planejamento, projeto e controle de sistemas de gestão da qualidade, } \\
\text { considerando a gestão por processos, a abordagem factual e a utilização de } \\
\text { ferramentas específicas }\end{array}$ \\
\hline Engenharia do produto & $\begin{array}{l}\text { Ferramentas e processos envolvidos em atividades estratégicas e } \\
\text { operacionais de desenvolvimento de novos produtos }\end{array}$ \\
\hline Engenharia organizacional & $\begin{array}{l}\text { Conhecimentos relacionados com a gestão das organizações envolvendo o } \\
\text { planejamento estratégico e operacional }\end{array}$ \\
\hline Engenharia econômica & $\begin{array}{l}\text { Formulação, estimação e avaliação de resultados econômicos para avaliar } \\
\text { alternativas e respaldar a tomada de decisão com o uso de técnicas } \\
\text { matemáticas }\end{array}$ \\
\hline Engenharia do trabalho & $\begin{array}{l}\text { Projeto, aperfeiçoamento, implantação e avaliação de tarefas, sistemas de } \\
\text { trabalho de forma a garantir a saúde e integridade física do trabalhador }\end{array}$ \\
\hline $\begin{array}{l}\text { Educação em Engenharia de } \\
\text { Produção }\end{array}$ & $\begin{array}{l}\text { Desenvolvimento do.Estudo do Ensino de Engenharia de Produção, do } \\
\text { Estudo do Desenvolvimento e Aplicação da Pesquisa em Engenharia de } \\
\text { Produção, e avaliações sobre a Prática Profissional em Engenharia de } \\
\text { Produção }\end{array}$ \\
\hline $\begin{array}{l}\text { Planejamento da utlização eficiente de recursos naturais, destinação e } \\
\text { tratamento de resíduos e implantação de sistema de gestão ambiental e } \\
\text { responsabilidade social }\end{array}$ \\
\hline
\end{tabular}

Quadro 1 - Subáreas de conhecimento da engenharia de produção Fonte: ABEPRO (2008)

Como se pode perceber, com o apoio do Quadro 1, há uma diversidade de subáreas nas quais o futuro profissional de engenharia de produção assim como o estudante, através do estágio curricular supervisionado, podem atuar. E essa característica da EP cria uma oportunidade de experimentação sem igual para o futuro profissional, onde ele identifica suas afinidades e preferências desde o início das atividades de estágio até a sua formação propriamente dita.

Pode-se dizer que uma outra vantagem desse processo dinâmico de experimentação, que alimenta o processo de ensino-aprendizagem, é a oportunidade de escolhas mais maduras no que tange à participação em atividades de extensão e pesquisa das quais os discentes desejam ou precisam fazer parte para concluir seus estudos.

\subsection{Mercado de trabalho e as demandas por pesquisa}

Analisando os dados do Ministério do Trabalho durante o período de 1997 a 2003, Faria (2004) mostra informações ligadas à evolução dos postos de trabalho ocupados por engenheiros de produção em diversos segmentos do mercado. A partir dos dados analisados, constatou-se que cerca de $45 \%$ dos engenheiros ocupam atividades relacionadas a área de serviços, ficando o restante distribuídos em áreas como indústria e comércio. Seguindo o mesmo raciocínio, Costa (2009) analisa dados da RAIS, revelando que o número de engenheiros na indústria é muito inferior se comparado à quantidade de profissionais inseridos na área de serviços.

Nigro e Valente (2008) apontam que o número de postos de trabalho ocupados por engenheiros no setor de serviços é grande e tende a crescer. Deste modo, pode-se concluir que o setor de serviços tem absorvido um grande número de profissionais graduados em engenharia. $\mathrm{Ou}$ seja, as vagas existentes no setor de serviços, provavelmente, estão ocupadas por profissionais de 
alguma base tecnológica sendo que os graduados em engenharia de produção teriam, teoricamente, mais competências voltadas às necessidades do setor de serviços que outras engenharias.

Pensando sobre a perspectiva de que o Engenheiro de Produção possui perfil profissional capaz de incrementar a capacidade competitiva das organizações, sejam elas industriais, de serviço, comerciais ou qualquer outro tipo, se confere a este profissional a competência de elevar a produtividade dos recursos, via solução de problemas. Fae e Ribeiro (2005) apontam a Engenharia de Produção como área de formação que conduz seus egressos à resolução de problemas característicos da Engenharia, o que viabiliza o profissional a gerenciar e maximizar a utilização dos recursos técnicos existentes e necessários na organização.

Pensar na resolução de problemas exige a reflexão sobre quais tipos são os mais relevantes, quais devem ser priorizados por garantir contribuição efetiva. Pensando nesta linha de raciocínio e correlacionando a pesquisa acadêmica a contribuição que ela pode prover, Nunes et al.(2015) propõe uma maior produtividade das pesquisas do programa de mestrado PPGEP da UFSM se as linhas de pesquisa tivessem maior afinidade com a realidade produtiva local, ou seja, que as pesquisas fossem ajustadas aos interesses das indústrias locais e/ou regionais.

As demandas locais e as do mercado de trabalho podem refletir sobre o tipo de produção científica de um curso de graduação e do perfil de egresso que está sendo formado. Segundo Mello e Santos (2015) as instituições de ensino superior têm papel fundamental no processo de formação do profissional e devem sempre buscar meios de manterem-se atualizadas, desde que respeitadas suas particularidades e limitações, com conteúdos e métodos de ensino que incentivem o conhecimento e o devido aprofundamento nos mais distintos campos do conhecimento que a Engenharia de Produção proporciona.

\section{MATERIAIS E MÉTODOS}

O estudo se caracteriza como um trabalho documental, descritivo-exploratório, que trata de dados que foram coletados dos projetos de final de um curso de Engenharia de Produção de uma instituição de ensino superior federal localizada no município de Nova Iguaçu, Rio de Janeiro.

A pesquisa pretende, a partir dos trabalhos desenvolvidos pelos formandos do curso, realizar um estudo bibliométrico, identificando as áreas de formação do curso que mais foram objeto de investigação pelos alunos, bem como identificar o foco dos textos e as motivações para a definição e escolha do tema. Araújo (2006) define bibliometria como a "aplicação de técnicas estatísticas e matemáticas para descrever aspectos da literatura e de outros meios de comunicação". O mesmo autor ainda indica que o termo "Bibliometria" popularizou-se em 1969 com a publicação do artigo clássico de Pritchard discutindo a polêmica "bibliografia estatística ou bibliometria?".

Para Silva et al (2011), o pilar da bibliometria é a análise da atividade científica ou técnica pelos estudos quantitativos das publicações, através de contagens estatísticas de publicações ou de elementos que reúnem uma série de técnicas estatísticas, buscando quantificar os processos de comunicação escrita. Para Vanti (2002) bibliometria é um conjunto de métodos de pesquisa desenvolvido pela Biblioteconomia e pelas Ciências da Informação, que através de análises quantitativa, estatística e de visualização de dados mapeia a estrutura do conhecimento de um campo científico, além de funcionar como uma ferramenta de análise das tendências dos pesquisadores em suas decisões na construção do conhecimento.

Segundo Pritchard (1969), as principais características da pesquisa bibliométrica são:

1. Identificar as tendências e crescimento do conhecimento com base em uma matéria; 
2. Estudar dispersão e obsolescências de certos assuntos científicos;

3. Medir impacto dos estudos publicados e as informações disseminadas no meio acadêmico;

4. Quantificar a cobertura das revistas cientificas;

5. Identificar autores e instituições mais produtivos

Para Muniz Jr et al. (2011), a pesquisa acadêmica consiste em uma análise crítica de trabalhos publicados anteriormente sobre o tema, tornando possível mapear o que já foi escrito sobre o tema, gerando sustentação para novas abordagens.

A metodologia aplicada teve as seguintes etapas: Pesquisa bibliográfica sobre a temática, definição das condições de coleta de dados, coleta de dados utilizando os trabalhos de fim de curso dos alunos entre 2010 e 2014, identificação das áreas da Engenharia de Produção tratada por cada estudo, tratamento estatístico e elaboração das tabelas e figuras em Excel, identificação e análise dos resultados encontrados.

\section{RESULTADOS E DISCUSSÃO}

O estudo tratou 38 trabalhos, distribuídos entre os anos de 2010 a 2014. A analise dos dados possibilitou identificar que 3 áreas da Engenharia de Produção inspiraram mais que 60\% de todos os trabalhos de fim de curso. As áreas Engenharia de Qualidade, Logística e Engenharia Organizacional foram as mais estudadas. A figura 1 apresenta a distribuição de frequência de cada área da Engenharia de Produção.

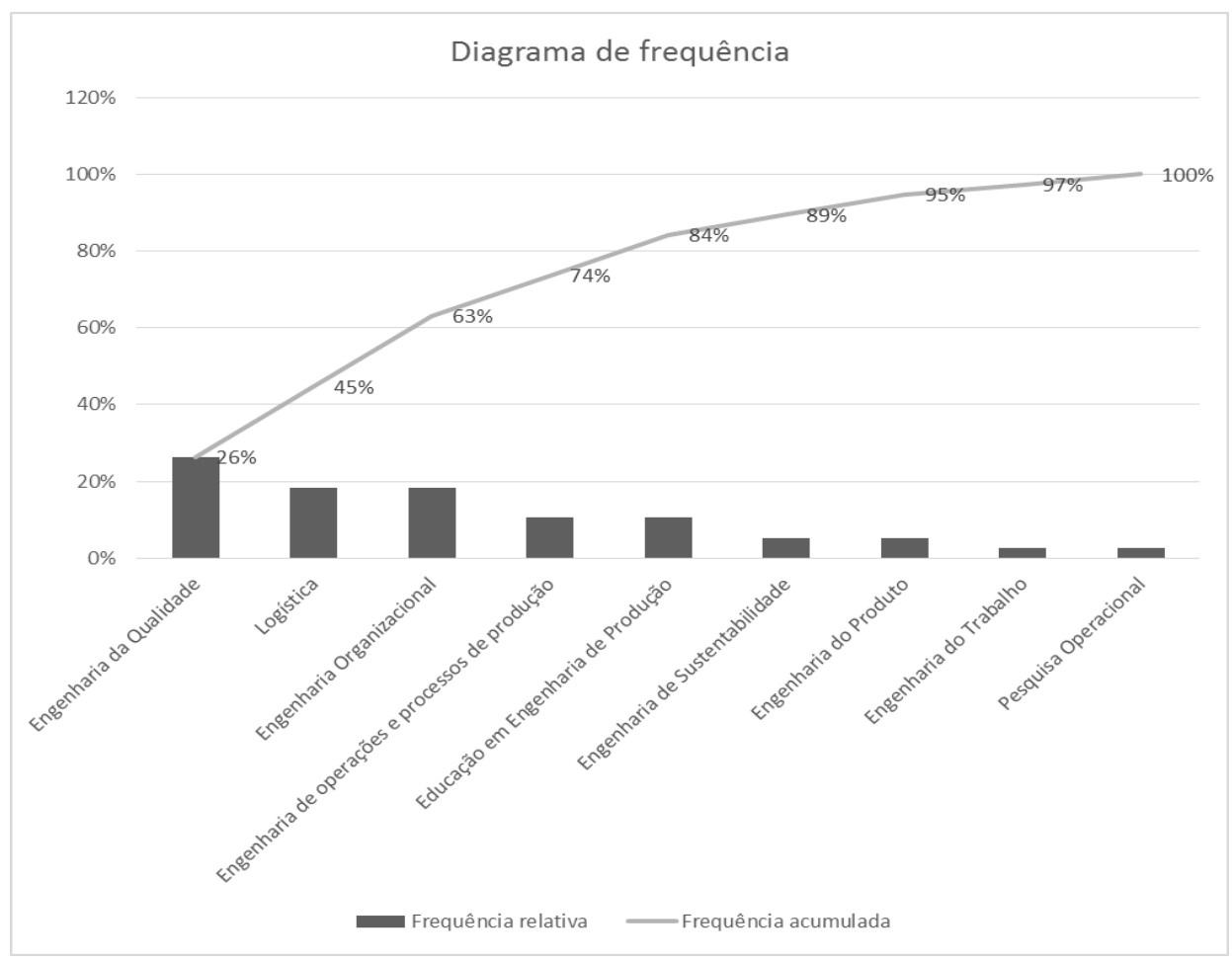

Figura 1- Orientações por Área entre 2010 e 2014

Percebe-se que as áreas mais recorrentes utilizadas nos projetos finais são Engenharia da Qualidade, Logística e Engenharia Organizacional, as quais juntas somam mais de $60 \%$ dos 
trabalhos. Também se observa que a área de Engenharia Econômica tem sido pouco demandada pelos alunos, muito devido aos alunos verem dificuldades em desenvolver uma temática na área.

A Engenharia da Qualidade, representada por $26 \%$ dos projetos, é responsável por planejar, projetar e controlar os sistemas de gestão da qualidade, promover o gerenciamento por processos e fazer uso de ferramentas da Qualidade para gestão e auxílio à tomada de decisões (ABEPRO, 2008). Nesta perspectiva, a Engenharia da Qualidade se torna, relevante para os alunos, sendo uma das áreas na qual se têm concentrado mais esforços, visando alcançar os requisitos dos clientes, o ganho de escala, confiabilidade e reduzir custos, justificando o maior interesse por parte dos autores.

Já a área de Logística, com 19\%, se torna importante por ser responsável pela organização do transporte, movimentação, estoque e armazenamento de insumos e produtos, de maneira a reduzir custos e garantir a disposição do produto ao cliente e seus níveis de exigência (ABEPRO, 2008). É uma das áreas cuja demanda por parte das empresas cresceu significativamente nos últimos anos e, consequentemente, este fator se refletiu no interesse por parte dos estudantes nesta linha de investigação.

\subsection{Engenharia da Qualidade}

Os trabalhos sobre Engenharia da Qualidade iniciaram-se em 2011, ano em que foram contabilizados três trabalhos, no ano seguinte 2012 o número de trabalhos caiu para um, número que permaneceu em 2013 e em 2014 este número cresceu para quatro.

A figura 2, abaixo, aponta que a subárea Planejamento e Controle da Qualidade se apresenta como a de maior demanda, com $56 \%$ do total identificado. Uma concentração temática associada ao interesse de formação e pesquisa dos docentes da área existentes no curso.

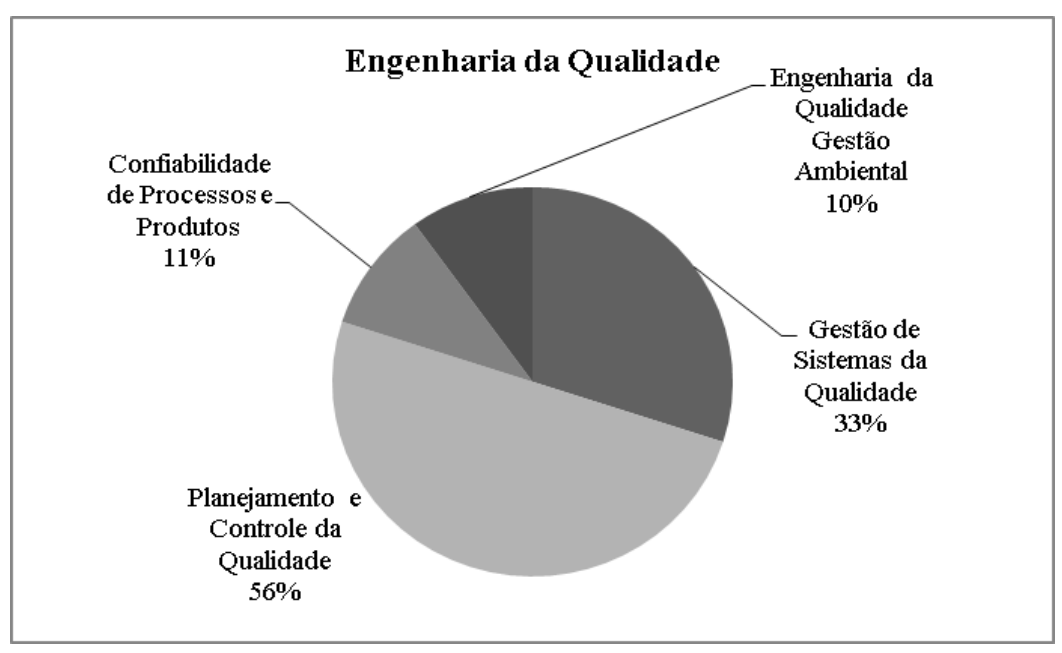

Figura 2 - Distribuição de frequência por subárea da Engenharia da Qualidade

\subsection{Logística}

No ano de 2011 foram defendidos os primeiros quatro trabalhos sobre o tema Logística. No ano 2012 não houve nenhum trabalho sobre o assunto, em 2013 o número de trabalhos subiu para três e em 2014 novamente o contabilizaram-se zero trabalhos. É possível perceber redução da 
procura dos estudantes por temas voltados a Logística, assunto que hoje ocupa o segundo lugar no ranking dos mais motivadores, porém percebe-se um movimento cíclico.

A figura 3 aponta para um balanceamento temático com as 4 sub-áreas tendo sido objeto de estudo, uma diversidade potencialmente motivada pelo docente que parece ter levado os alunos a trajetórias temáticas mais diversas.

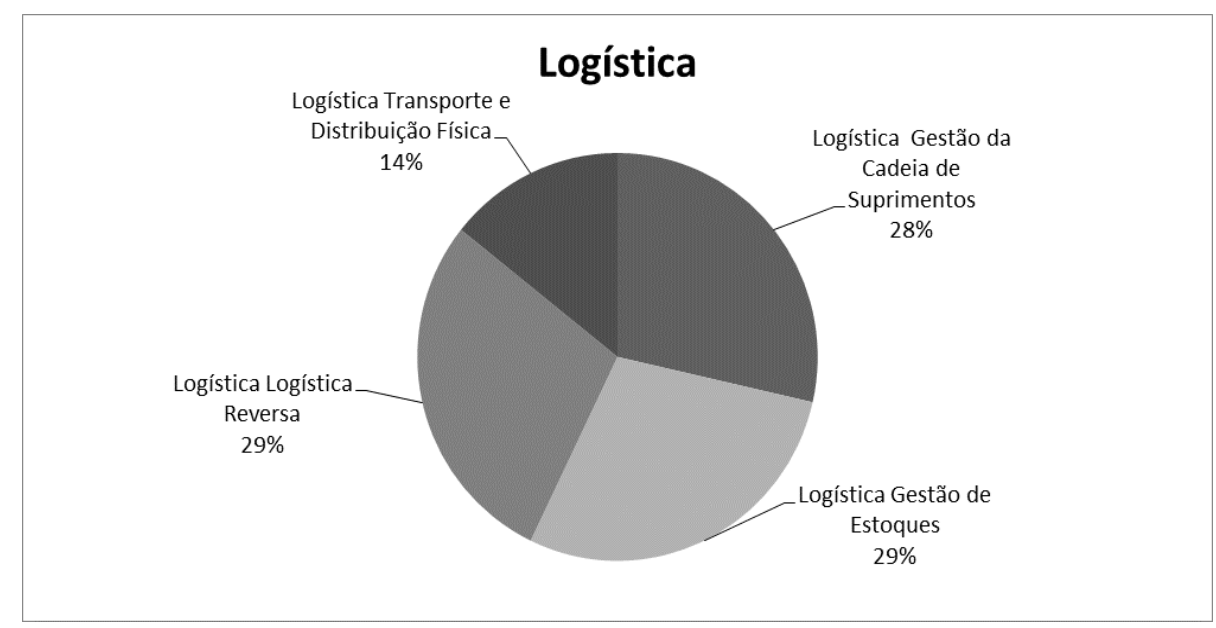

Figura 3 - Distribuição de frequência por subárea da Logística

\subsection{Engenharia Organizacional}

$\mathrm{Na}$ área da Engenharia Organizacional, o primeiro trabalho foi contabilizado no ano de 2010. Entre os anos 2010 e 2012 o número manteve-se na faixa entre um e dois trabalhos, respectivamente. No ano 2013 o número aumentou para três e no ano 2014 não houve nenhum trabalho.

A figura 4 aponta que a subárea Engenharia Organizacional Gestão Estratégica e Organizacional apresenta-se como a de maior demanda, com $72 \%$ do total identificado. As outras duas subáreas seguem uma tendência de serem pouco exploradas.

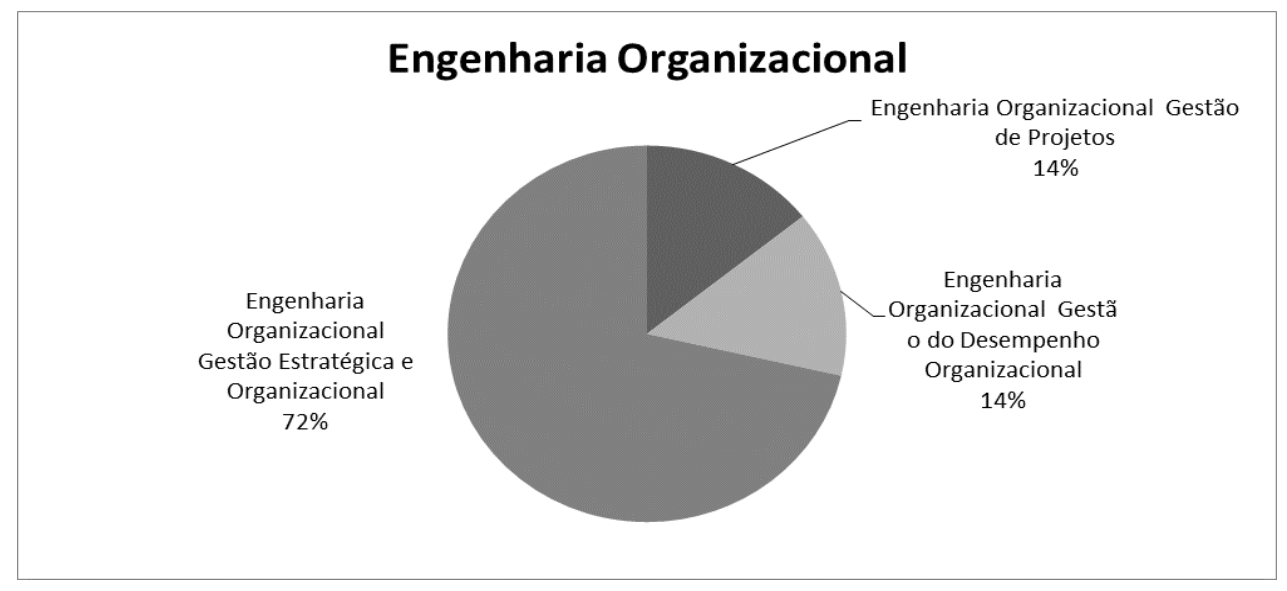

Figura 4 - Distribuição de frequência por subárea da Engenharia Organizacional.

\subsection{Engenharia de operações e processos de produção}

$\mathrm{Na}$ área de Engenharia de operações e processos de produção o número de trabalhos manteve-se estável entre os anos 2010 e 2014, contabilizando um trabalho em cada ano. 
A figura 5 aponta que a subárea Planejamento, Programação e Controle da Produção se apresenta como a de maior demanda, com $75 \%$ do total identificado. A subárea Gestão de Sistemas de Produção e Operações compõe a área com os demais 25\% de estudos realizados.

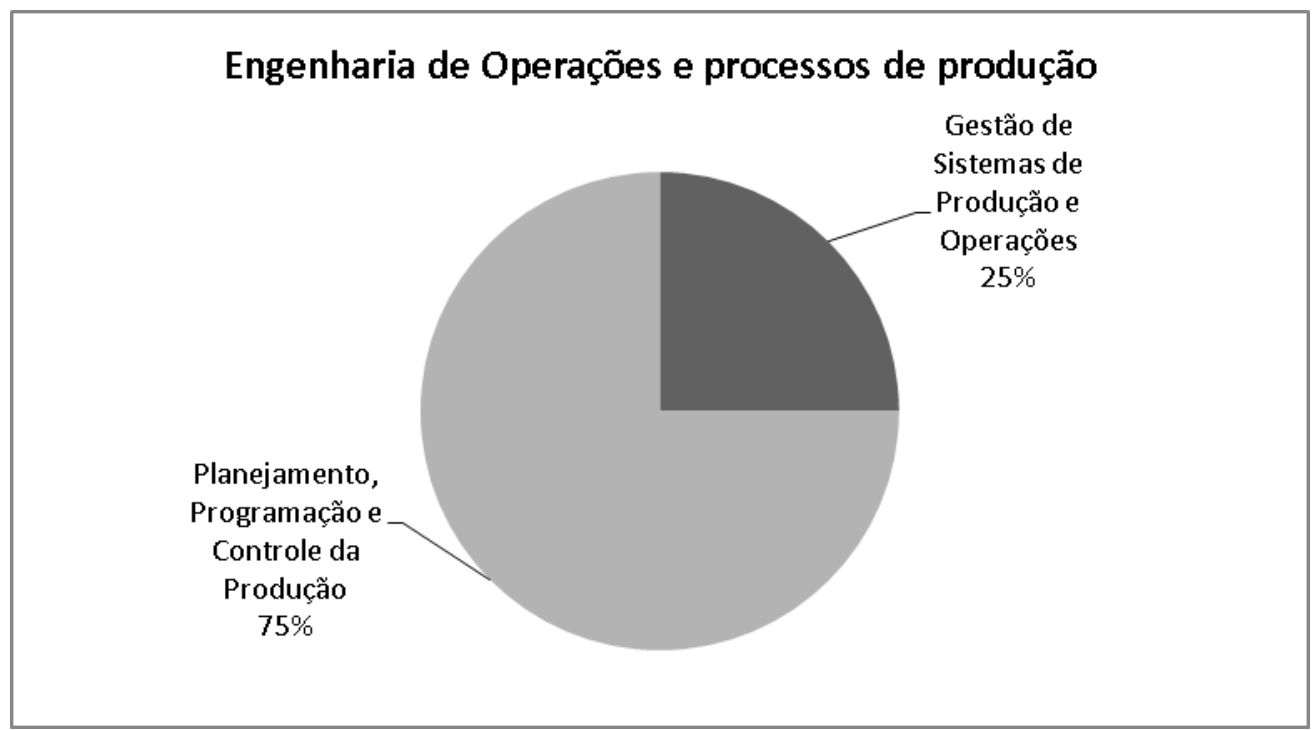

Figura 5 - Distribuição de frequência por subárea da Engenharia de Operações e processos de produção.

\subsection{Educação em Engenharia de Produção}

A área de Educação em EP, um dos ramos mais recentes, mostra que tem havido maior interesse dos estudantes pelo assunto, tendo o número de trabalhos duplicado entre os anos 2013 e 2014. Isto demonstra que o tema educação tem sido interesse de alguns alunos, o que poderá representar tendência a geração de novos docentes.

A figura 6 apresenta um balanceamento das subáreas, sendo todas exploradas em volume similar, $25 \%$, sendo uma representatividade interessante devido ao interesse que os alunos tem apresentado quanto a sua formação e ao mercado de trabalho.

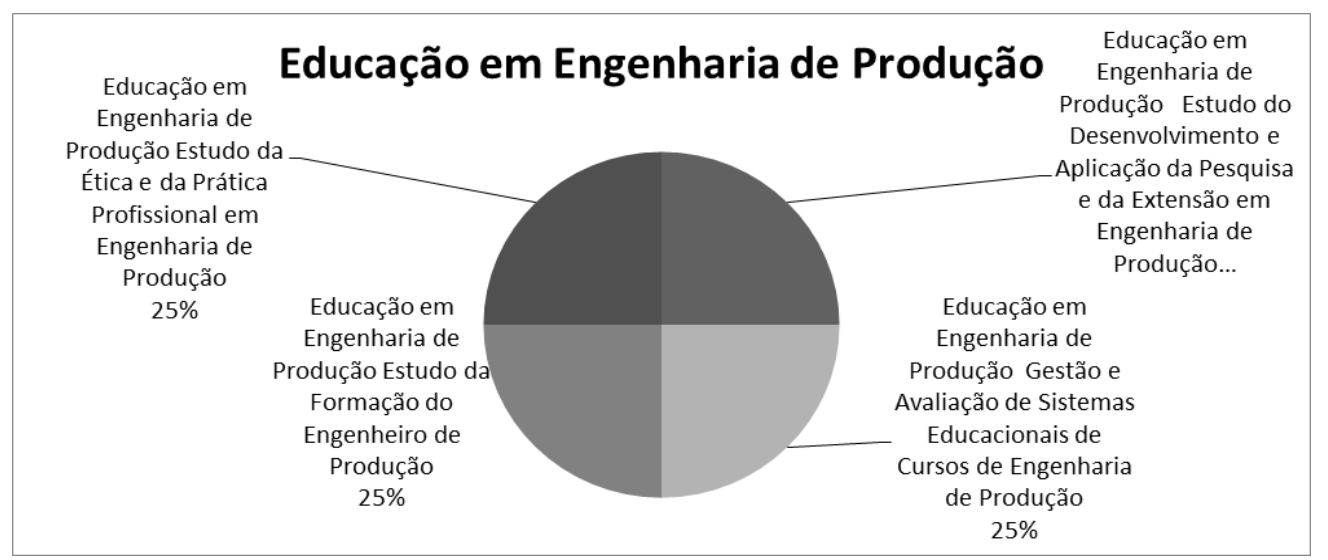

Figura 6 - Distribuição de frequência por subárea da Educação em Engenharia de Produção. 


\subsection{Demais áreas da Engenharia de Produção}

Na área de Engenharia da Sustentabilidade, não é possível estabelecer nenhuma tendência para com o assunto, tendo o último trabalho na área ter sido elaborado em 2011.

$\mathrm{Na}$ área de Engenharia do Produto, os dois primeiros trabalhos foram contabilizados em 2014 com foco em planejamento e projeto do produto. Existe uma tendência que nos próximos anos o interesse dos alunos pelo assunto cresça em virtude da necessidade de criação de novos produtos e advento da inovação.

$\mathrm{Na}$ área de Engenharia do Trabalho o primeiro projeto foi contabilizado em 2014 com foco em ergonomia. De uma maneira geral, com a necessidade das empresas adequarem-se cada vez mais ao nível de segurança e saúde dos trabalhadores, o interesse por este assunto venha a crescer, motivando mais estudantes a pesquisarem sobre o assunto.

$\mathrm{Na}$ área de Pesquisa Operacional, apenas foi contabilizado um trabalho no ano 2013. Não é possível perceber qualquer tendência para com o assunto, embora seja uma das áreas de maior rentabilidade dentro da EP.

\subsection{Desenvolvimento e motivação para o projeto final}

A indústria é o ramo que tem atraído mais estudantes para desenvolverem suas pesquisas. A forte aplicação da Engenharia de Produção em atividades de produção industrial faz com que muitos estudantes sintam-se atraídos pela atividade manufatureira para ser o pano de fundo de seus trabalhos. Por ser uma engenharia de aplicação em vários ramos de atividade, os setores e comércio e serviços também foram referenciados pelos graduandos. Na figura 7 é possível obter a frequência dos trabalhos por tipos de atividade. Neste trabalho serão considerados três áreas: Serviços, Comércio e Indústria.

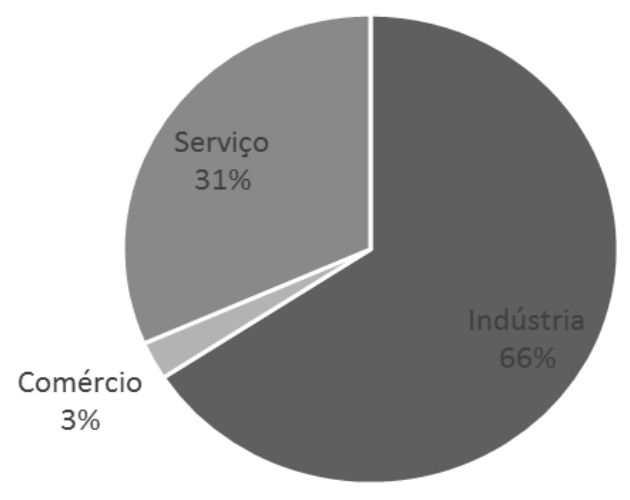

Figura 7 - Frequência de trabalhos com base nos tipos de atividade

Quanto a motivação pela elaboração dos trabalhos, figura 8, se tem que apenas $15 \%$ dos trabalhos foram motivados pelas atividades desenvolvidas em estágios, momento fundamental durante a formação acadêmica dos estudantes, na qual ele vê como se dá a interface teoria x prática, ou seja, a relação da graduação com as empresas. Grande parte dos graduandos iniciam suas carreiras no estágio, sendo a porta de entrada para o mundo corporativo.

A confecção do trabalho final de graduação é visto como uma oportunidade para apresentar ideias de melhoria para as empresas nas quais o estudante desenvolve sua atividade de estágio, de maneira a fornecer combustível para trabalhos científicos e pesquisas desenvolvidas na graduação. 


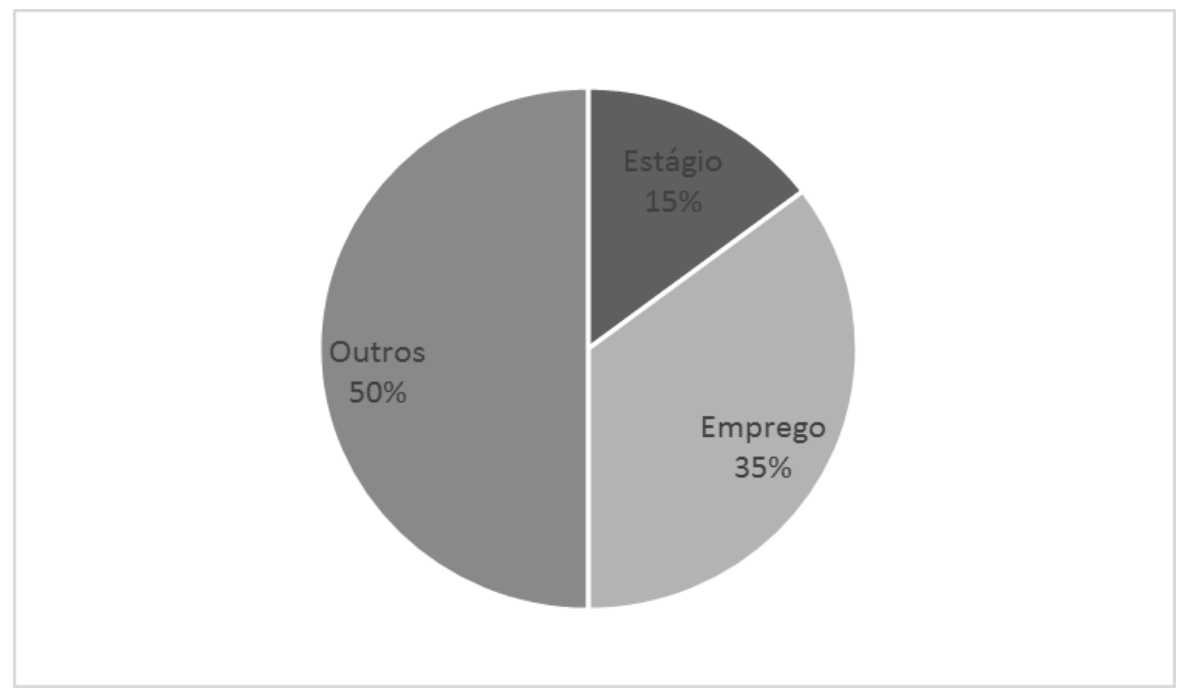

Figura 8 - Motivação para elaboração dos trabalhos finais

O emprego enquanto motivação representou $35 \%$ dos trabalhos. Esta justificativa é análoga a do estágio: os estudantes veem em seu emprego uma oportunidade de melhoria ou análise e desenvolvem seus trabalhos visando estudar tais situações.

$\mathrm{Na}$ categoria "outros", cuja frequência é a mais elevada, é justificada por fatores como preferência pelo assunto, curiosidade, necessidade de aprimorar o conteúdo visto nas disciplinas, interesse em seguir no ramo de pesquisa em cursos de pós-graduação, dentre outros fatores de natureza intrínseca ao graduando.

A tabela 1 permite correlacionar a área econômica que se realiza o estudo com a motivação baseada nas empregabilidades dos autores (emprego ou estágio). Também permite visualizar que mais que $60 \%$ dos estudos foram realizados nas atividades industriais e que destes, mais que $50 \%$ fizeram seus trabalhos baseados em problemas das empresas que estavam estagiando ou trabalhando como emprego formal. A tabela também permite verificar que $34 \%$ dos estudos foram desenvolvidos no setor de serviços, sendo que mais que $60 \%$ destes tendo sido motivados não por interesse relacionado a empregabilidade, mas por motivos naturais que tem significado pessoal, do foro intimo o que mostra a vocação em pesquisa que o curso desenvolve e estimula em seus egressos.

Tabela 1- Relação entre Emprego/Estágio e área do projeto final de curso

\begin{tabular}{|l|c|c|c|c|}
\hline Área & Emprego & Estágio & Outros & Total Geral \\
\hline Comércio & $0,00 \%$ & $2,63 \%$ & $0,00 \%$ & $2,63 \%$ \\
\hline Indústria & $26,32 \%$ & $7,89 \%$ & $28,95 \%$ & $63,16 \%$ \\
\hline Serviço & $5,26 \%$ & $7,89 \%$ & $21,05 \%$ & $34,21 \%$ \\
\hline Total Geral & $\mathbf{3 1 , 5 8 \%}$ & $\mathbf{1 8 , 4 2 \%}$ & $\mathbf{5 0 , 0 0 \%}$ & $\mathbf{1 0 0 , 0 0 \%}$ \\
\hline
\end{tabular}

De uma maneira geral, mesmo o curso não ofertando disciplinas na área de serviços, os alunos se atraem pela temática, a medida que vivenciam experiências em uma grande metrópole que lhes desagradam. Percebem-se situações problema que se tornam alvo para suas pesquisas, induzindo parte dos alunos para uma área de atuação não tão tradicional quanto aos que desenvolvem estudos na área industrial, trabalho que fica facilitado até mesmo em função da maior diversidade de bibliografia sobre tais temas, ou seja, se torna mais fácil, atraente e seguro, investir esforço acadêmico em áreas com maior quantidade de referencias bibliográficas. 
Ainda com relação a motivação baseada nas janelas de oportunidade ofertadas pelos professores, se tem que houve um certo balanceamento em relação as orientações do grupo em questão. A tabela 2 permite observar que alguns professores se destacam por atrair mais alunos a temas relativos a suas matérias, visto que os alunos se empregam nas áreas e acabam desenvolvendo interesse em aprofundar seus estudos em casos aplicados à empresa que estão trabalhando ou estagiando.

Tabela 2- Relação Professores e volumes de orientações

\begin{tabular}{|c|c|}
\hline Professor & \% de orientações \\
\hline A & $21 \%$ \\
\hline B & $18 \%$ \\
\hline C & $11 \%$ \\
\hline D & $24 \%$ \\
\hline E & $5 \%$ \\
\hline F & $16 \%$ \\
\hline G & $5 \%$ \\
\hline
\end{tabular}

Trazendo o olhar aos princípios do processo de interiorização se percebe que o objetivo desejado tem sido alcançado, pois se desenvolve na região, além de formação em ensino superior, conhecimento sobre a região, sobre empresas da região, e contribui para o mercado de trabalho local por desenvolver mão de obra local qualificada e capaz de desenvolver projetos de Engenharia.

\section{CONCLUSÃO}

Através de uma analise bibliométrica, o estudo possibilitou identificar que no curso de Engenharia de Produção da unidade descentralizada Nova Iguaçu, as áreas temáticas de Engenharia da Qualidade, Logística e Engenharia Organizacional, como as que mais atraíram e motivaram os alunos. Outras áreas foram pouco acionadas, mas se posicionam de forma promissora, visto que o curso está em fase de desenvolvimento e consolidação do corpo docente.

Acredita-se que a experiência proporcionada pelos estágios e empregos produza grande motivação nos alunos quando eles tiverem que escolher seus temas de monografia. Entretanto, a parte dos alunos que escolhem realizar seus estudos também é relevante, ou seja, há um balanceamento dos quantitativos. O que é válido ressaltar é que a indústria, para o grupo de estudo, se apresenta como o elemento central de motivação. A vocação do curso se apresenta de forma a consolidar o projeto de formação, mas a analise bibliométrica possibilitou verificar que a área de serviços não deve ser desconsiderada, que ela se apresenta em volume real, e efetivo, justificando estudos mais apurados e oferta de disciplinas direcionadas a apoiar os alunos na consolidação temática.

Como resultados têm-se que mais que $60 \%$ dos estudos foram realizados nas atividades industriais e que destes, mais que $50 \%$ fizeram seus trabalhos baseados em problemas das empresas que estavam estagiando ou trabalhando como emprego formal. Também é possível verificar que $34 \%$ dos estudos foram desenvolvidos no setor de serviços, sendo que mais que $60 \%$ destes tendo sido motivados não por interesse relacionado a empregabilidade, mas por motivos naturais que tem significado pessoal.

Como estudos futuros aponta-se a necessidade de se realizar um estudo qualitativo que possa identificar outros fatores motivadores para escolha dos temas de projeto final, criar mecanismos que 
possibilitem maior diversidade de áreas sendo contempladas nas pesquisas dos alunos. Também se sugere uma analise comparativa com outras instituições de ensino interiorizadas, identificando semelhanças e divergências.

\section{REFERENCIAS}

ABEPRO - Associação Brasileira de Engenharia de Produção. Áreas e Sub-áreas da Engenharia de Produção. 2008. Disponível em <http://www.abepro.org.br/interna.asp?p=399\&m=424\&s=1\&c=362>. Acesso em: 7 jul. 2014.

BURIOLLA, M. A. F. O estágio supervisionado. 6a ${ }^{\text {a }}$ Ed. São Paulo: Cortez, 2009.

COSTA, M.A. e OLIVEIRA, V.F. Um estudo sobre a Engenharia de Produção e suas ênfases. In: XVI SIMPEP Simpósio de Engenharia de Produção, Anais..., 2009.

DIAS, J.N., ARAUJO, F.O. Indissociabilidade ensino-pesquisa-extensão: contribuições de projeto de engenharia de produção à promoção do desenvolvimento local. In: XXVIII ENCONTRO NACIONAL DE ENGENHARIA DE PRODUÇÃO. Anais..., Rio de Janeiro, Brasil, 2008.

FAE, C.S., RIBEIRO, J.L.D. Um retrato da Engenharia de Produção no Brasil. Revista Gestão Industrial, v.1, n.3, p.24-33, 2005.

FARIA, A.F. Informações referentes à adequação curricular dos cursos de engenharia de produção. In: XXIV Encontro Nacional de Engenharia de Produção. Anais... Florianópolis, Novembro, 2004.

MELLO, J.A.V.B.; SANTOS, V.J.D. A formação acadêmica em Engenharia de Produção, a demanda do mercado e as unidades curriculares de Instituições de Educação Superior públicas do Rio de Janeiro. Exacta - EP, São Paulo, v.13, n.1, p. 55-66, 2015.

MELLO, J.A.V.B., SOUSA, F.R. Caminhos formacionais na engenharia de produção: a formação docente e os resultados do ENADE 2011. Revista GUAL, Florianópolis, v.8, n. 2, p. 200-215, maio 2015

MUNIZ Jr., J.; MAIA, F.G.M.; VIOLA, G. Os principais trabalhos na teoria do conhecimento tácito: pesquisa bibliométrica 2000-2011. In: XIV Simpósio de Administração da Produção, Logística e Operações Internacionais. Anais... São Paulo: 2011.

NIGRO, I.S.C., VALENTE, U.G. Engenharia de produção no Brasil: vagas criadas, egressos e mercado de trabalho. In: XXVIII ENCONTRO NACIONAL DE ENGENHARIA DE PRODUÇÃO, Anais... 2008.

NUNES, C.F., WEISE, A.D., MEDEIROS, F.S.B. Uma proposta de alinhamento das áreas de pesquisa em um programa de Pós-Graduação em Engenharia de Produção. Revista Produção e Desenvolvimento, v.1, n.2, p.44-55, mai/ago, 2015.

OLIVEIRA, Vanderlí Fava de. A avaliação dos cursos de Engenharia de Produção. Revista Gestão Industrial, v.1, n.3, p.1-12, 2005.

PIRES, R.C.; GONÇALVES, S.G.; FARIA, L.C.; ARAUJO, F.O. CEFET/RJ - UnED/ NI: Experiência e Desafios da Interiorização do Ensino Público Federal. XI Encontro de Engenharia de Produção da UFRJ. Anais... Rio de Janeiro: Poli/ UFRJ, 2007.

PRITCHARD, A. Statistical bibliorgrahy or bibliometricas?. Journal of documentation, v. 25, n. 4, p. 348-349, 1969.

VANTI, N.A.P. Da bibliometria à webometria: uma exploração conceitual dos mecanismos utilizados para medir o registro da informação e a difusão do conhecimento. Ciência da informação, v.31, n.2, p.152-162, 2002. 